\title{
MEASUREMENT OF THE FLOW IN CORONARY ARTERY BYPASS GRAFTS
}

\author{
Petr Nemec ${ }^{a}$, Vilem Bruk, Andrea Steriovsky, Marek Gwozdzeiwicz, Roman Hajek \\ ${ }^{a}$ Department of Cardiac Surgery, Faculty of Medicine, Palacký University, University Hospital, Olomouc, Czech Republic \\ e-mail:petr.nemec@fnol.cz
}

Received: April 28, 2006; Accepted: May 20, 2006

Key words: Coronary artery bypass/Flow measurement/Internal thoracic artery/Y graft

The aim of our study was to measure the flow in coronary artery bypass grafts and to compare the flow between two groups of patients. In group A the arterial revascularization was performed with both internal thoracic arteries using as a Y graft and in group B conventional revascularization using left internal thoracic artery (ITA) attached to the left anterior descending artery (LAD) and venous grafts to the other branches of the left coronary artery was performed. The flow in all grafts was measured at six time points during the operation. The cumulative flow at the end of the operation in the group A (arterial Y graft) was $51.8 \pm 24.5 \mathrm{ml} / \mathrm{min}$ and in group B (conventional technique) it was $96.8 \pm 41.1 \mathrm{ml} / \mathrm{min}(\mathrm{p}<0.05)$. The flow in left ITA to LAD was similar in both groups $(27.3 \pm 15.9 \mathrm{ml} / \mathrm{min}$ and $26.3 \pm 16.1 \mathrm{ml} / \mathrm{min}$ in group A and B). The flow in right ITA $(25.2 \pm 18.4 \mathrm{ml} / \mathrm{min})$ was significantly lower than in venous grafts $(72.5 \pm 45.5 \mathrm{ml} / \mathrm{min})$. The calculated flow reserve was 2.2 in group A and 2.1 in group B. We found that the cumulative flow in arterial Y graft was lower in comparison with conventional revascularization. This is due to the lower flow in the right ITA branch of the Y graft compared to venous grafts. However based on clinical results, we can postulate that the flow in the Y graft is sufficient to meet the demand of the myocardium originally supplied by the left coronary artery.

\section{INTRODUCTION}

Myocardial revascularization in the left coronary artery territory using internal thoracic arteries is a well-established method based on clinical experience with excellent long-term results ${ }^{1-3}$. The $\mathrm{Y}$ graft techniques have been developed with different free arterial conduits attached to the side of in situ left internal thoracic artery (ITA) that serves as a single inflow source. The right ITA or the radial arteries are the most often used conduits. Since often more than two distal anastomoses are required, a sequential grafting technique is adopted. However, some doubts about the adequacy of the flow immediately after revascularisation may exist in such a technique. Little is also known about the competition between blood flow in the grafts and native coronary arteries.

The aim of our study was to compare the blood flow in the grafts between two groups of patients. In group A arterial revascularization with both internal thoracic arteries was performed and in group B conventional revascularization with the left ITA attached to the left anterior descending artery (LAD) and venous graft to the other branches of the left coronary artery was used. The flow reserve of the grafts was calculated.

\section{MATERIAL AND METHODS}

Over a 1-year period between September 2004 and September 2005, 123 patients with coronary artery disease having a first time coronary artery bypass grafting
(CABG) were enrolled into the study. There were 105 male and 18 female, average age $59.0 \pm 5.4$ years (4377 years). The patients suffered from at least two vessel diseases (both branches of left coronary artery). They were divided into two groups.

Group A consists of patients with only arterial revascularization of the left coronary artery. Both internal thoracic arteries were taken in a skeletonized fashion. The right ITA was harvested as a free graft and anastomozed end-to-side to the left ITA forming a Y graft. The graft was sprayed and wrapped in sponge soaked in diluted papaverine solution. All the branches in the left coronary territory were revascularized with this type of graft. The left ITA was used for revascularization of the anterior wall of the left ventricle and the right ITA for revascularization of the lateral wall. Since often more than two distal anastomoses were required, a sequential grafting technique was adopted

In group B the conventional revascularisation was performed with left ITA taken as a pedicle. The ITA was also sprayed and wrapped in sponge soaked in diluted papaverine solution after the harvest. It was attached to LAD during the procedure. Venous grafts bypassed the other diseased branches of the left coronary artery.

The operations were performed in cardiopulmonary bypass in mild hypothermia using crystalloid cardioplegia. The distal anastomoses were done first. After removal of the aortic clamp, the proximal anastomoses were performed on a side-biting clamp.

Graft flow was measured with the transit-time method using the CardioMed Flowmeter CM 1005 (Medi-Stim 
Table 1. Comparison of the flow and PI of left ITA in group A and B.

\begin{tabular}{|l|c|c|c|c|}
\hline \multirow{2}{*}{} & \multicolumn{2}{|c|}{ Group A } & \multicolumn{2}{c|}{ Group B } \\
\cline { 2 - 5 } & Flow (ml/min) & PI & Flow $(\mathrm{ml} / \mathrm{m})$ & PI \\
\hline (1) Beginning of the harvest & $20.9 \pm 7.5$ & $4.2 \pm 1.8$ & $16.5 \pm 7.5^{*}$ & $4.6 \pm 3.8$ \\
\hline (2) End of the harvest & $34.1 \pm 28.8$ & n.d. & $24.8 \pm 14.1^{*}$ & n.d. \\
\hline (3) Before distal anastomosis & $73.3 \pm 51.6$ & n.d. & $51.7 \pm 31.1^{*}$ & n.d. \\
\hline (4) After distal anastomosis & $65.1 \pm 37.8$ & $0.3 \pm 0.3$ & $46.6 \pm 29.4^{*}$ & $0.6 \pm 0.8$ \\
\hline (5) After clamp removal & $37.9 \pm 25.3$ & $1.1 \pm 1.2$ & $26.5 \pm 17.5^{*}$ & $1.7 \pm 1.3^{*}$ \\
\hline (6) End of the operation & $27.3 \pm 15.9$ & $2.4 \pm 1.4$ & $26.3 \pm 16.1$ & $2.5 \pm 1.5$ \\
\hline
\end{tabular}

${ }^{*} \mathrm{p}<0.05$, PI - pulsatile index, n.d. - not detectable

Table 2. Comparison of the flow and PI in right ITA and venous grafts in group A and B.

\begin{tabular}{|l|c|c|c|c|}
\hline \multirow{2}{*}{} & \multicolumn{2}{|c|}{ Group A } & \multicolumn{2}{c|}{ Group B } \\
\cline { 2 - 5 } & Flow & PI & Flow & PI \\
\hline (1) Beginning of the harvest & $21.6 \pm 9.1$ & $4.1 \pm 1.9$ & n.d. & n.d. \\
\hline (2) End of the harvest & $35.4 \pm 23.5$ & n.d. & n.d. & n.d. \\
\hline (4) After distal anastomosis & $57.7 \pm 30.2$ & $0.4 \pm 0.7$ & $156.7 \pm 92.6^{*}$ & $1.7 \pm 1.4$ \\
\hline (5) After clamp removal & $28.9 \pm 18.9$ & $1.4 \pm 1.2$ & $89.0 \pm 67.0^{*}$ & $2.7 \pm 2.8$ \\
\hline (6) End of the operation & $25.2 \pm 18.4$ & $2.9 \pm 4.4$ & $72.5 \pm 45.5^{*}$ & $2.7 \pm 2.3$ \\
\hline
\end{tabular}

${ }^{*} \mathrm{p}<0.05$, PI - pulsatile index, n.d. - not detectable

Table 3. Comparison of the cumulative flow in group A and B.

\begin{tabular}{|l|c|c|}
\hline \multirow{2}{*}{} & Group A & Group B \\
\cline { 2 - 3 } & Flow (ml/min) & Flow (ml/min) \\
\hline (4) After distal anastomosis & $115.2 \pm 40.9$ & $207.6 \pm 105.2^{*}$ \\
\hline (5) After clamp removal & $70.3 \pm 33.5$ & $115.4 \pm 57.9^{*}$ \\
\hline (6) End of the operation & $51.8 \pm 24.5$ & $96.8 \pm 41.1^{*}$ \\
\hline
\end{tabular}

${ }^{*} \mathrm{p}<0.05$

A/S, Oslo, Norway). Probes of 2, 3 or $4 \mathrm{~mm}$ were used in order to fit the actual size of the vessels. The measurement were taken at six time points: (1) at the beginning of the harvest of each ITA, (2) free flow at the end of the harvest of each ITA, (3) free flow immediately before distal anastomosis construction, (4) after completing all the distal anastomosis with the aortic clamp in place, (5) after removal of the aortic clamp and (6) at the end of the procedure before closing the sternum. The pulsatile index
(PI), which reflects the relationship between systolic and diastolic flow, was calculated at each time point.

For each measurement an attempt was made to maintain a similar mean arterial pressure.

The results were expressed as mean values \pm standard deviation. The statistical analysis was performed using an unpaired t-test and p-values of equal to or less than 0.05 were considered statistically significant. 


\section{RESULTS}

The comparison of the flow in left ITA in groups A and B is shown in Tab. 1. The flow in skeletonised ITA in group A was significantly higher than in the pedicled ITA in group B at all time points but the final flow at the end of the operation, which was $27.3 \pm 15.9 \mathrm{ml} / \mathrm{min}$ in group A and $26.3 \pm 16.1 \mathrm{ml} / \mathrm{min}$ in group B. The PI had the tendency to higher values in group B, but statistical significance was reached only after clamp removal (measurement No 5).

The flow in the right ITA (group A) and venous grafts (group B) i.e. the grafts bypassing the other diseased left coronary branches are shown in Tab. 2. The flow in the venous grafts was significantly higher.

Similar results were found when total flow in all grafts was compared between both groups. The cumulative flow in the conventional technique of revascularization was $96.8 \pm 41.1 \mathrm{ml} / \mathrm{min}$ and it was significantly higher, than the flow of $51.8 \pm 24.5 \mathrm{ml} / \mathrm{min}$ in the arterial revascularization (Tab. 3).

However, the calculated flow reserve was similar in both groups: 2.2 and 2.1 in group A and B respectively.

\section{DISCUSSION}

Early graft occlusion after CABG may have deleterious consequence. It is associated with a high risk of postoperative myocardial infarction and hemodynamic instability. Intraoperative measurement of the graft blood flow is not only a useful quality parameter for revealing technical errors but also provides important hemodynamic information that can improve our knowledge of the physiological aspects of CABG.

The measurement of the blood flow in left ITA in both groups showed higher flow in group A in measurement $1-5$. This could be caused by the skeletonization technique used in this group. However, the concomitant higher values of PI indexes in group B indicate that higher peripheral vascular resistance may also play a role in these results. The reason for the higher vascular resistance is not known. One explanation could be higher flow in venous grafts in these patients causing increased flow competition with ITA graft resulting in increased PI.

The higher flow in the skeletonised ITA implies that the surgeon does not need to fear ITA spasm during gentle harvesting. This is in agreement with the finding of sympathetic denervation and increased sensitivity to sodium nitroprusside of the skeletonized ITA in vitro ${ }^{4}$.

Nevertheless, only the flow in the graft at the end of the procedure is of real importance. This represents not only the flow capacity of the conduit and peripheral vascular resistance, but also the quality of the anastomosis and degree of competition with the native flow. The influence of all these factors on the long- term outcome should be assessed during follow-up. This flow was similar in both groups, but the absolute value was somewhat lower compared to the literature ${ }^{5-7}$.
In arterial revascularization the composite $\mathrm{Y}$ graft method has gained increasing popularity ${ }^{3,8}$. It can be constructed using different arterial conduits: right ITA, radial artery, inferior epigastric artery or right gastroepiploic artery. The branches of the left coronary artery are the most often used territory for such revascularization, but all three coronary beds can be revascularized as well ${ }^{9}$. The flow in the Y graft is assumed to be sufficient to meet the requirement of the heart during exertion ${ }^{8}$.

The arterial conduit flow reserve was calculated by dividing the maximum potential flow by the actual flow at the end of the operation. This was found to be 2.2, which is in agreement with the literature ${ }^{9-11}$. Gaudino reported a similar result, even if the calculation was made after dobutamine injection ${ }^{8}$. This indicates that there is a considerable reserve allowing for increased flow during times of increased requirements, such as exercise ${ }^{11}$. Tagusari also showed good early adaptation of the left ITA based on the angiographic measurement of the diameter of left ITA before and after operation ${ }^{12}$.

There is a dearth of information comparing the flow between arteries and veins to the same vascular territory. Our results showed significantly higher flow in venous grafts compared to right ITA to the lateral wall of the left ventricle. Hassanein published a $35 \%$ increase in flow to LAD comparing left ITA to venous graft, but no difference was found in the revascularization of the obtuse marginal artery? ${ }^{7}$ By contrast Leong showed no difference in bypass flow to LAD in ITA compared to venous graft ${ }^{13}$.

In our study we found the cumulative flow in arterial $Y$ graft significantly lower in comparison to conventional revascularization combining left ITA to LAD and venous grafts to the other left coronary artery branches. This is due to the lower flow in the right ITA branch of the $\mathrm{Y}$ graft compared to venous grafts. The flow in the left ITA anastomozed to LAD was not different. All our patients suffered from stable angina and were operated according to an elective schedule. We failed to find any signs of hypoperfusion preoperatively. Therefore we can postulate that the flow in the Y graft is sufficient to meet the demand of the myocardium supplied by left coronary artery in such a group of patients. However, it needs to be proved, if the arterial Y graft is sufficient to provide adequate flow also in the situations connected with increased demands (unstable angina, ongoing myocardial infarction, etc.). In the meantime the use of venous grafts in such a situation owing to their higher flow may be more reliable.

\section{ACKNOWLEDGEMENT}

This work was supported by grant No NR 7791-3/2004 of IGA, Ministry of Health, Czech Republic.

\section{REFERENCES}

1. Loop FD. (1998) Coronary artery surgery: the end of the begin- 
ning. Eur J Cardio-thorac Surg 14, 554-571.

2. Lytle BW, Blackstone EH, Loop FD, Houghtaling PL, Arnold JH, Akhrass R, McCarthy PM, Cosgrove DM. (1999) Two internal thoracic artery grafts are better than one. J Thorac Cardiovasc Surg $117,855-872$

3. Pevni D, Kramer A, Paz Y, Lev-Run O, Locker Ch, Metsa M, Shapira I, Mohr R. (2001) Composite arterial grafting with double skeletonised internal thoracic arteries. Eur J Cardio-thorac Surg 20, 299-304.

4. Deja MA, Golba KS, Malinowski M, Wos S, Kolowca M, Biernat J, Kajor M, Spyt TJ (2005) Skeletonization of internal thoracic artery affects its innervation and reactivity. Eur J Cardio-thorac Surg 28, 551-557.

5. Walpoth BH, Mohadjer A, Gersbach P, Rogulanko R, Walpoth BN, Althuas U. (1996) Intraoperative internal mammary artery transit-time flow measurements: comparative evaluation of two surgical pedicle preparation techniques. Eur J Cardio-thorac Surg 10, 1064-1070.

6. Canver CHC, Dame NA. (1994) Ultrasonic assessment of internal thoracic artery graft flow in the revascularized heart. Ann Thorac Surg 58, 135-138.

7. Hassanein W, Albert AA, Arnrich B, Walter J, Ennker IC, Rossendahl U, Bauer S, Ennker J. (2005) Intraoperative transit time flow measurement: Off-pump versus on-pump coronary artery bypass. Ann Thorac Surg 80, 2155-2161.
8. Gaudino M, Di Mauro M, Iaco AL, Canosa C, Vitolla G, Calafiore AM. (2003) Immediate flow reserve of $Y$ thoracic artery grafts: an intraoperative flowmetric study. J Thorac Cardiovasc Surg 126, 1076-1079.

9. Royse AG, Royse CF, Groves KL, Bus B, Yu G. (1999) Blood flow in composite arterial grafts and effect of native coronary flow. Ann Thorac Surg 68, 1619-1622.

10. Delatore JR, Theman TE, Garzia FM. (1999) Intraoperative flow rate measurement of T-grafts: calculation a flow reserve. Heart Surg Forum 2, 235-238.

11. Speziale G, Ruvolo G, Coppola R, Marino B. (2000) Intraoperative flow measurement in composite $\mathrm{Y}$ arterial grafts. Eur J Cardiothorac Surg 17, 505-508.

12. Tagusari O, Kobayashi J, Bando K, Niwaya K, Nakajima H, Ishida M, Nakatani T, Yagihara T, Kitamura S. (2003) Early adaptation of the left internal thoracic artery as a blood source of Y-composite radial artery grafts in off-pump coronary artery bypass grafting. Heart Surg Forum 6, E93-98.

13. Leong DKH, Ashok V, Nishkantha A, Shang YH, Sim EKW. (2005) Transit-time flow measurement is essential in coronary artery bypass grafting. Ann Thorac Surg 79, 854-857. 